\title{
FORMAÇÃO CONTINUADA: TEDÊNCIAS E PERSPECTIVAS
}

\author{
Alípio Rodrigues de Sousa Neto \\ Professor do Campus Avançado de Jataí/UFG \\ e-mail alipio.neto@brturbo.com.br
}

Resumo: No cenário educacional brasileiro dos anos 90 ocorreu a proliferação de projetos e programas de formação continuada no Brasil, os quais tem sido incentivados e implementados tanto pelo sistema público como privado de ensino, bem como por sindicatos de trabalhadores em educação e por editoras de livros didáticos. Cada um desses órgãos ou instituições possuem interesses na formação continuada de educadores que, em muitos casos, apresentam profundas divergências de concepções. Na verdade, essas divergências evidenciam interesses diversos por parte daqueles que patrocinam esse tipo de formação. No plano legal, tais iniciativas tem sustentação na própria Lei de Diretrizes e Bases em seu artigo 67. Nesse sentido, consideramos importante discutirmos a formação continuada, não somente para evidenciarmos concepções, posturas ou visões divergentes mas, fundamentalmente, para abrirmos um processo de discussão sobre a necessidade de se estruturar um projeto de formação continuada do educador no Campus Avançado de Jataí.

Palavras-chaves: formação continuada; políticas educacionais; profissionalização do educador.

Follow up studies: Tendencies and Perspectives.

Abstract : Lots of projects and programs of follow up studies have been happening in Brazil throughout the 1990's in the context of the Brazilian Educational scenery. Many of them have been incentivated and created both by public or private instituitions, as well as teachers unions and printing houses. Each one of these instituitions have great interested in the follow up studies done by teachers, which in most cases present deep diverging conceptions. In fact, these different conceptions clearly convey the aims of all those instituitions whose objective is to supply this kind of teaching formation. Legally, These work have been upholded by the LDB ( Lei de Diretrizes e Bases, em seu artigo 67.) Thus, considering how important it is to discurss the follow up studies matter, not only to clarify conceptions, postures, or even diverging points of view, but mainly to open a discurssion process, specially designed for the need of structuring a follow up studying project involving the professor staff from Campus Avançado de Jataí.

Key words: Follow up studies; Educational politics ; Teacher's professional improvement. 


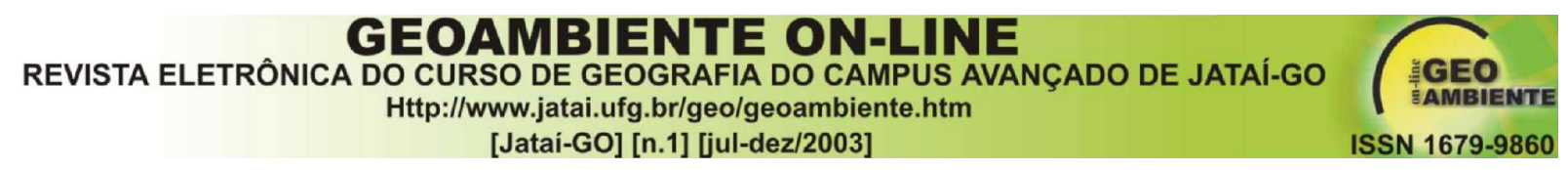

\section{1 - Introdução}

O mundo vem passando por transformações decorrentes, entre outras questões, do processo de globalização, acelerado pelo desenvolvimento de tecnologias nas áreas de comunicação, transporte e no setor produtivo, o que tem provocado uma reordenação no mundo do trabalho. O novo mercado globalizado passa a exigir a formação de um profissional de novo tipo, com disponibilidade de trabalhar em grupo, com facilidade de comunicação, flexível no processo de produção, com capacidade de adaptação às inovações tecnológicas, em permanente processo de atualização. Tal necessidade de formação deste trabalhador, tem pressionado os sistemas educacionais do mundo inteiro, provocando uma reorientação dos objetivos da escola, na medida em que esta passa a ser percebida como o lócus fundamental para a construção das habilidades exigidas pelo mercado de trabalho. Desta forma, acentua-se o interesse do capital pela melhoria da qualidade da educação, principalmente da educação básica, a qual deve atingir o maior contingente possível da população em idade escolar.

Particularmente no Brasil, chegamos a um índice de mais de 95\% de matrículas de crianças e adolescentes na faixa de 7 a 14 anos no ensino fundamental, o que demonstra um certo esforço do governo federal (com resultados questionáveis) no sentido de ampliar as oportunidades educacionais ${ }^{1}$. Busca-se, assim, um aumento da escolaridade da população brasileira, ao mesmo tempo em que a política educacional implementada no país tem buscado construir um novo padrão de qualidade na educação, difundindo propostas curriculares, analisando livros didáticos, avaliando o sistema educacional.

Nesse cenário educacional, assistimos, principalmente no transcorrer dos anos 90, a proliferação de projetos e programas de formação continuada no Brasil, os quais tem sido incentivados e implementados tanto pelo sistema público com privado de ensino, bem como por sindicatos de trabalhadores em educação e por editoras de livros didáticos. Cada um desses órgãos ou instituições possuem interesses na formação continuada de educadores que, em muitos

\footnotetext{
${ }^{1}$ Tal constatação não significa dizer que estamos atingindo a universalização do ensino. Ao mesmo tempo em que se ampliam as oportunidades educacionais, dados divulgados por Secretarias de Educação e pela literatura especializada evidenciam que o fracasso escolar (evasão e repetência) tem atingido índices ainda altos. Assim, embora o sistema educacional tenha crescido quantitativamente, a escola brasileira não tem conseguido manter em suas salas de aulas boa parte dos alunos que nela ingressaram. Por outro lado, a precária formação dos profissionais do ensino, aliado aos baixos salários e péssimas condições de trabalho, tem dificultado a reestruturação do ensino e, conseqüentemente, a melhoria do processo ensino-aprendizagem nas escolas do país.
} 


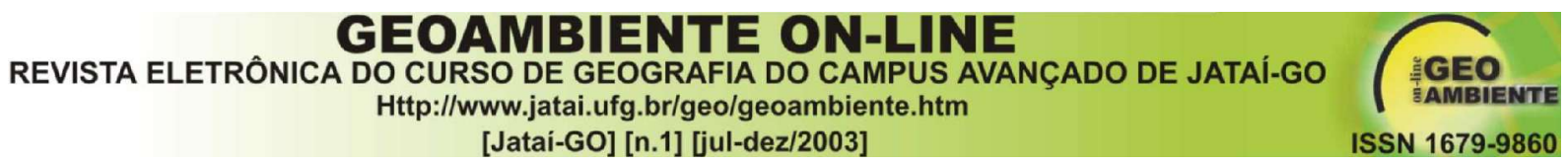

casos, apresentam profundas divergências de concepção. $\mathrm{Na}$ verdade, essas divergências evidenciam interesses diversos por parte daqueles que patrocinam esse tipo de formação.

No plano legal, tais iniciativas tem sustentação na própria Lei de Diretrizes e Bases que, em seu artigo 67 estabelece que:

Os sistemas de ensino promoverão a valorização dos profissionais da educação, assegurando-lhes, inclusive nos termos dos estatutos e dos planos de carreira do magistério público: (...) II - aperfeiçoamento profissional continuado, inclusive com licenciamento periódico remunerado para esse fim² ${ }^{2}$.

Desta forma, torna-se importante discutirmos a formação continuada dos profissionais da educação, não somente para evidenciarmos concepções, posturas ou visões divergentes mas, fundamentalmente, para abrirmos um processo de discussão sobre a necessidade de se estruturar um projeto de formação continuada do educador no Campus Avançado de Jataí/ Universidade Federal de Goiás (CAJ/UFG), capaz de articular ações em torno de princípios e objetivos comuns à instituição no que diz respeito a esse tipo de formação.

\section{2 - FUNDAMENTOS PARA A CONSTRUÇÃO DE UM PROJETO DE FORMAÇÃO CONTINUADA DE EDUCADORES}

Em texto publicado em 1991, TARDIF e outros discutem a relação dos docentes com diversos saberes que intervêm na prática desses profissionais. Entre outras questões, nos colocam o saber docente como sendo composto por vários saberes de origem diversificada. Nas palavras dos autores: "o saber docente se compõe na verdade de vários saberes provenientes de diferentes fontes. Esses saberes são saberes das disciplinas, os saberes curriculares, os saberes profissionais (compreendendo as ciências da educação e a pedagogia) e os da experiência" (1991: 216). Também, destacam que "mesmo ocupando uma posição estratégica no interior dos saberes sociais, o corpo docente é desvalorizado face aos saberes que possui e transmite" (1991: 216).

\footnotetext{
${ }^{2}$ A Lei de Diretrizes e Bases do Sistema Educativo do estado de Goiás, Lei Complementar no 26 , de 28 de dezembro de 1998, estabelece, com relação à formação continuada de profissionais da educação o que se segue: Art. 91 - O período reservado aos docentes da educação básica, das redes pública e privada para estudos, planejamento e avaliação, não pode ser inferior a 1/3 (um terço) do trabalho em sala de aula. Art. 95 - O poder público garantirá aos profissionais da educação condições e incentivos à formação continuada do seu quadro em efetivo exercício, sem prejuízo do previsto no artigo 91 desta lei.
} 


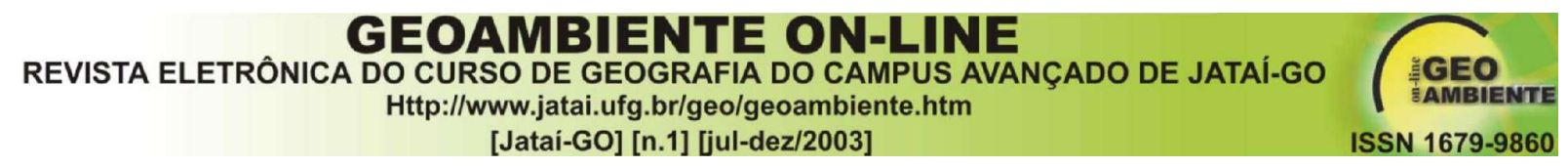

Ainda, discutem a relevância dos saberes da experiência para os professores, o que os constitui e a sua importância como meio de deterem algum controle sobre a sua prática. Colocam que os saberes da experiência não "provém das instituições de formação ou dos currículos" e sequer encontram-se sistematizados no quadro de doutrinas ou teorias, pois originam-se da prática da profissão docente que se desenvolve em situações concretas já:

que exigem uma cota de improvisação e de habilidade pessoal, bem como capacidade de enfrentar situações mais ou menos transitórias e variáveis. Ora, a experiência dessas limitações e dessas situações é formadora: somente ela permite ao docente desenvolver os habitus (isto é disposições adquiridas na e pela prática real), que lhe permitirão justamente enfrentar as limitações e os imponderáveis da profissão (1991: 228).

Os autores destacam que é o saber da experiência profissional que filtra os outros saberes retirando-lhes o que é útil, avaliando-os a partir das condições de trabalho. É importante destacar que, ao contrário dos outros saberes, o professor mantém uma relação de interioridade com o saber da experiência, pois é construído nas interações com os pares, na instituição na qual trabalha. Ao se desvalorizar o saber proveniente da experiência se está, na verdade, se desvalorizando um saber que os docentes consideram como sendo os "fundamentos da prática e da competência profissional". Assim, "diante desta situação, os saberes da experiência surgem como núcleo vital do saber docente, a partir do qual o(a)s professor(a)s tentam transformar suas relações de exterioridade dos saberes em relação de interioridade com sua própria prática" (1991: 232).

Como decorrência do exposto torna-se importante pensar a formação inicial não como determinante da atuação profissional mas como um elemento a mais na formação do professor. Mais ainda, torna-se importante repensar as políticas de formação continuada implementadas pelas instituições formadoras de profissionais para a educação. Essas questões fertilizam a discussão sobre o papel da formação inicial na carreira do profissional docente bem como nos permite refletir com maior cuidado e profundidade sobre as políticas de formação continuada implementadas pelos órgãos e instituições responsáveis pela formação dos educadores.

Ratificando o exposto acima, LUDKE (1996) nos apresenta alguns resultados de pesquisa onde discute a socialização do professor, focalizando sua formação e o exercício da ocupação profissional. 


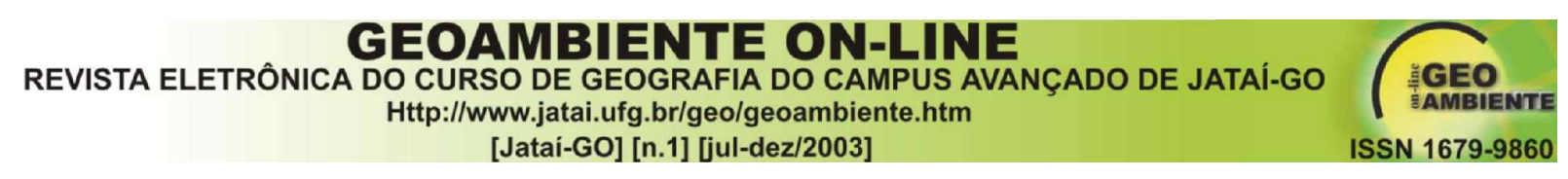

Nesse trabalho, afirma-se que os professores defendem com muita ênfase a formação inicial o que surpreendeu a equipe de pesquisadores: "Embora esperássemos uma voz crítica em uníssono expressando uma visão negativa unindo nossos entrevistados, em relação aos dois cursos, surpreendemo-nos com a avaliação bastante positiva sobre o que aprenderam no curso Normal e também na licenciatura" (1996: 10).

No entanto, a autora constata uma visão pouco clara dos professores no que diz respeito à formação inicial nos comentários complementares às posições positivas que defendiam ao se referirem ao curso Normal e de Licenciatura. Para os professores o que aprenderam durante a sua formação inicial foi muito útil no início de suas carreiras mas, com o passar do tempo, muito do aprendido foi deixado de lado como decorrência de outros aprendizados ocorridos na prática da profissão.

Comentando a necessidade de se esclarecer a especificidade da formação inicial a autora nos coloca a seguinte posição:

O que nos ocorre, como sugestão explicativa no momento, é a importância de assinalar a formação inicial, como o nome diz, como preparação apenas inicial. Ela não deveria ser sobrecarregada com o que não the é compatível e para o que não esta aparelhada (...) Se fosse reconhecido claramente o caráter introdutório de uma preparação que não pretende ser total nem visualizar toda a carreira do professor, talvez ela pudesse se tornar mais efetiva, assumindo a especificidade desse caráter inicial (1996: 11)3.

Como se pode perceber, a formação inicial é um momento fundamental na formação do profissional/educador. No entanto, a dinâmica inerente à prática docente, a relação do educador com o cotidiano da sala de aula, com o cotidiano da unidade escolar, também assume um caráter formador. São os saberes da experiência, já destacados anteriormente.

SANTOS (1999) ainda nos chama a atenção para o fato de que além da experiência prática oferecer "critérios para a recontextualização dos saberes docentes, em função das especificidades do contexto escolar, também os valores e princípios políticos e morais do

\footnotetext{
${ }^{3}$ Como decorrência destas discussões, o Campus Avançado de Jataí/Universidade Federal de Goiás (CAJ/UFG) tem empreendido esforços no sentido de estabelecer com clareza princípios e ações que dêem sustentação a uma política de formação permanente do profissional educador, aqui entendida como sendo "o processo de desenvolvimento profissional permanente [que] inclui formação inicial e continuada, concebida de forma articulada" (Referenciais para Formação de Professores, 1999: 19). No entanto, em função dos objetivos deste trabalho não apresentaremos as discussões realizadas no Campus Avançado de Jataí/Universidade Federal de Goiás sobre o processo de formação inicial do profissional da educação, o que será objeto de um outro trabalho.
} 


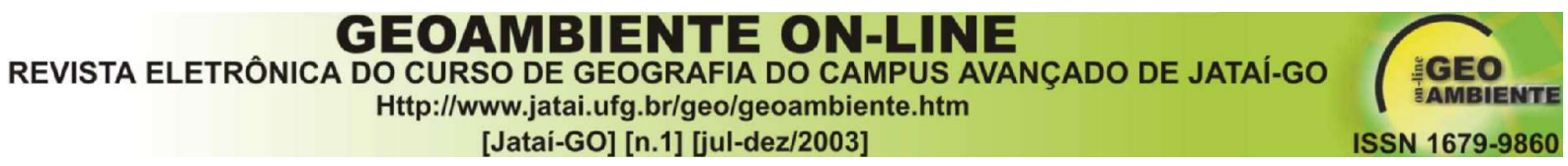

professor são referências que influenciam na tomada de decisões e nas formas como conduz sua prática pedagógica (1999: 04).

Assim, os projetos de formação continuada devem, necessariamente, tematizar as práticas já realizadas pelos profissionais da educação, tornando-a objeto de observação e análise de tal forma que seja oferecido uma maior fundamentação e um maior nível de aprofundamento possibilitando ao educador a reflexão sobre a sua prática profissional e, conseqüentemente, um nível maior de autonomia para a produção de conhecimentos profissionais (REFERENCIAIS PARA FORMAÇÃO DE PROFESSORES: 131). Nesse caso, os saberes que se originam da prática profissional não serão vistos como estranhos e indesejáveis diante de "projetos educacionais inovadores" mas como fundamentos para repensar a atuação do profissional/educador. Somente se reconhecendo os saberes provenientes da experiência como legítimos é que uma política de formação continuada pode alcançar sucesso, já que evitará sobrepor um "discurso acadêmico", de caráter autoritário, à realidade vivenciada e aos saberes provenientes da prática do educador.

\section{3 - FORMAÇÃO CONTINUADA: algumas classificações necessárias}

Nesse ponto do trabalho, buscaremos fazer uma distinção entre os diversos projetos de formação continuada já que os processos de formação do educador podem assumir objetivos, conteúdos e formas distintas. Para tanto, nos utilizaremos, principalmente, do trabalho de SANTOS (1999) no qual a autora discute a formação contínua ou formação em serviço do profissional/educador.

Para essa autora os processos de formação continuada podem ser distinguidos de acordo com a origem da iniciativa, sendo possível identificar tanto iniciativas pessoais quanto institucionais, podendo ambas ser individuais ou coletivas.

A iniciativa pessoal de caráter individual ocorre quando o educador ingressa em cursos (especialização, mestrado, etc.) de acordo com o seu interesse em horário diferente do seu horário de trabalho. Já a iniciativa pessoal de caráter coletivo ocorre quando, por exemplo, grupos de professores(as) remuneram um profissional para lhes dar uma assessoria técnica, com o objetivo de ajuda-los a resolverem seus problemas de sala de aula (SANTOS, 1999: 05). Tanto a iniciativa 
pessoal de caráter individual como coletiva compartilham o fato de que são eles (a pessoa ou grupo) que assumem a despesa e a responsabilidade pela formação.

Quanto as iniciativas institucionais de caráter individual, esta ocorre quando a instituição "promove a qualificação de seus docentes, liberando-os total ou parcialmente de suas funções e/ou arcando com o pagamento das despesas para a realização, dentre outros, de estágios técnicos-científicos, cursos de especialização e pós-graduação (mestrado ou doutorado)" (SANTOS, 1999: 06). Já com relação às iniciativas institucionais de caráter coletivo são aquelas oferecidas aos educadores pelo sistema de ensino ou pelas escolas, podendo assumir a forma de cursos, seminários, semanas de estudos, etc. Nessas atividades a participação pode ser tanto voluntária como compulsória.

A iniciativa pessoal de caráter individual tem sido a forma principal de formação continuada dos profissionais da educação. Embora não possa nem deva ser cerceada, não nos parece ser o tipo de formação mais adequada se se pensa a melhoria da qualidade do ensino de forma mais ampla. Isso porque, geralmente o educador procura esse tipo de formação pensando essencialmente na melhoria salarial, secundarizando a preocupação com uma formação consistente, mais adequada às suas necessidades profissionais. Tal situação tem gerado uma enorme procura pelos profissionais da educação de cursos, principalmente por especializações, sendo esta demanda a base da proliferação de cursos oferecidos por diversas instituições, cuja qualidade, em muitos casos, é questionável. Ainda, demonstra a falta de uma política de formação institucional dos profissionais do ensino.

A iniciativa pessoal de caráter coletivo apresenta aspectos positivos na medida em que a iniciativa do grupo de professores decorre da necessidade de se buscar alternativas para superar problemas detectados na sua atuação profissional. Portanto, há a preocupação com uma melhor fundamentação capaz de ampliar a visão dos educadores sobre o problema, criando as condições para a construção de caminhos novos que os façam avançar na melhoria de sua atuação. Por outro lado, apresenta aspectos negativos já que se constitui em iniciativa de um grupo apenas, sendo o alcance dessa modalidade de formação bastante restrita. Ainda, existe um ônus, já que é o grupo que irá arcar com as despesas e responsabilidade de sua formação, tendo que se utilizar de tempo extra para discutir os problemas que o aflige.

Já as iniciativas institucionais de caráter individual apresentam pontos positivos já que essa modalidade de formação é assumida pela instituição, sendo que os profissionais podem ser 
liberados (parcial ou integralmente) de suas funções, o que significa dizer que o processo de busca de maior qualificação profissional ocorrerá sem o sacrifício do tempo livre ou de lazer. Além do mais, os educadores podem ter as despesas assumidas pela instituição, o que não é muito usual, pelo menos, por enquanto, no Brasil. Ainda, nessa modalidade de formação, a liberação ou não dos profissionais esta condicionada aos interesses da instituição, promotora da qualificação do quadro docente. No entanto, nesse tipo de formação não se atinge o conjunto dos educadores das diversas unidades escolares, o que limita o alcance do projeto de formação e de melhoria da qualidade da atuação do educador, o que não significa dizer que este tipo de formação deva ser negligenciado. As diversas unidades escolares possuem características próprias (qualificação profissional, estrutura física, heterogeneidade dos alunos, etc.), com problemas específicos, o que pode exigir um tratamento diferenciado de problemas que são específicos de uma escola. Assim, essa modalidade de formação aponta para a necessidade de se desenvolver novas estratégias, articulando formação continuada e prática educativa dos educadores no contexto de sua atuação, o que significa afirmar que a formação continuada do educador não pode ser (ou pelo menos não deveria ser) desvinculada da realidade educacional na qual atua, do cotidiano da escola, da necessidade de buscar respostas para problemas que emergem no dia-a-dia de cada unidade escolar.

Chegamos, então, a quarta modalidade de formação continuada, ou seja, as iniciativas institucionais de caráter coletivo que, segundo SANTOS (1999), pode partir das instituições ou do coletivo dos professores. Continua a autora:

No primeiro caso, a proposta de capacitação pode surgir em decorrência de um diagnóstico feito por dirigentes educacionais, tomando como referência o desempenho dos alunos, ou em função da necessidade de introdução de alguma mudança pedagógica. Para a realização desse tipo de formação, tanto no nível do sistema de ensino como das escolas, geralmente são contratadas pessoas de reconhecida competência em um campo, ou grupo de pessoas, ou mesmo, uma instituição que se encarrega de desenvolver o programa de capacitação. Neste caso, toda a programação é previamente discutida pelos indivíduos, grupos ou agências capacitadoras e as instâncias que demandam a formação (1999: 07).

Com relação ao segundo caso, "este se configura quando a demanda pela capacitação parte dos professores. Geralmente, estes solicitam o desenvolvimento de atividades de formação 
continuada quando se sentem inseguros em relação a determinados conteúdos ou à forma de ensina-los" (SANTOS, 1999: 07).

Embora a formação institucional de caráter coletivo de iniciativa das instituições atinjam educadores de diferentes procedências institucionais, possibilitando acesso à discussões sobre temas considerados relevantes a um grande número de profissionais da educação, algumas considerações devem ser feitas ao se pensar essa modalidade de formação. Nesse tipo de formação, geralmente a programação da capacitação (calendário, conteúdos a serem trabalhados, atividades a serem desenvolvidas, etc.) são elaborados com pouca ou nenhuma participação dos educadores o que tem acarretado uma série de críticas a esse tipo de iniciativa.

Segundo REALE e outros (1995) são os participantes (profissionais da educação) os responsáveis pela

transposição didática - do que foi supostamente aprendido - para o seu trabalho cotidiano em sala de aula, sem apoio dos agentes responsáveis pelos cursos. Além disso, freqüentemente esses cursos visam à implementação de novas propostas curriculares, supondo mudança de concepções e atitudes dos participantes - o que não ocorre simplesmente a partir da aquisição de novas informações (1995: 66).

Tal fato acarreta insegurança, já que os educadores se vêem impelidos a assumirem projetos educacionais que desconhecem, já que não participaram do processo de sua elaboração, e que, quase sempre, se chocam com a sua prática educativa, com as necessidades educacionais originadas no cotidiano no qual estão inseridos. Desta situação decorre uma crítica bastante comum entre os educadores participantes desta modalidade de formação que é a falta de conhecimento da realidade da escola por parte dos professores das universidades ou dos órgãos formadores, responsáveis pelo curso.

Retomando a discussão sobre a formação contínua do tipo institucional e coletiva, acreditamos que esta seja a modalidade de formação que mais interessa ao conjunto dos educadores "e sobre o qual as escolas podem ter controle no sentido de melhorar a qualidade de ensino" (SANTOS, 1999: 06). No entanto, é importante que se crie canais permanentes de discussão sobre os problemas educacionais envolvendo todos os segmentos ligados ao sistema educacional (Sindicato de Trabalhadores da Educação, Secretarias de Ensino, Conselhos Comunitários, Universidades, etc.) de tal forma que se possa elaborar uma política de formação continua dos profissionais da educação com base nas necessidades reais do sistema educacional, 


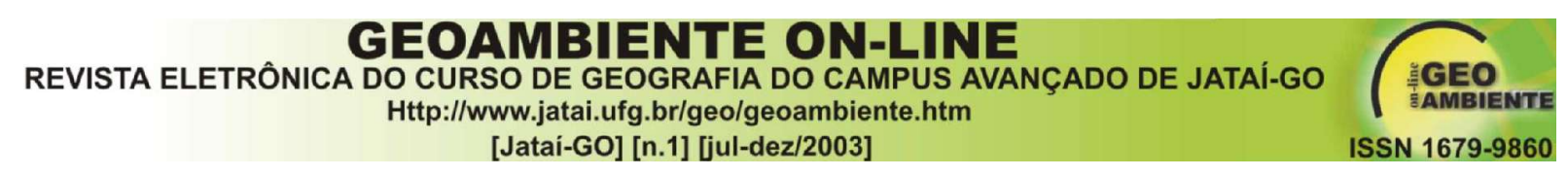

de uma forma geral, e das escolas, de forma mais específica. Pode-se, desta forma, levantar temas que são do interesse geral dos educadores bem como temas mais específicos de cada unidade escolar, ao mesmo tempo em que, de forma coletiva, pode-se traçar as ações necessárias para o atendimento das necessidades tanto gerais como específicas.

4 - AS ARMADILHAS DO CAMINHO: sobre as políticas de formação continuada de profissionais da educação

Como já afirmamos anteriormente, inúmeras são as visões que norteiam a estruturação e implementação de programas de formação continuada no país. Nesse momento do nosso trabalho discutiremos os diversos interesses envolvidos, por parte de órgãos e instituições (editoras, sindicatos de trabalhadores e governo federal), nesse tipo de formação.

Segundo SANTOS (1999):

o interesse das editoras nesse tipo de formação, claramente está relacionada à venda de livros e material didático. Uma análise mais rigorosa sobre a participação de editoras em programas de capacitação de docentes pode mostrar que esses programas podem, muitas vezes, estar mais relacionados a um processo de desqualificação do trabalho docente do que à qualificação do professorado. Inúmeros autores têm mostrado como a política de livros didáticos - verdadeiros manuais e guias do trabalho docente - serve para desqualificar o trabalho docente. Esses livros definem os conteúdos de ensino, sua organização e seqüência e a forma de transmissão, deixando pequena margem de autonomia para o docente (1999: 12).

No entanto, essa discussão deve ser ampliada na medida em que o governo federal, através do Ministério da Educação (MEC), tem estabelecido uma política educacional profundamente centralizadora a qual subordina o mercado editorial, bem como o conjunto dos educadores, às suas prescrições.

Atendendo ao Artigo 201 da Constituição Federal, “o governo federal passa pela primeira vez, em meados dos anos noventa, a fazer ele próprio prescrições sobre o currículo, que vão muito além das normas e orientações gerais que caracterizaram a atuação dos órgãos centrais em períodos anteriores" (BARRETO, 1998: 35). Desta forma, vem a tona os chamados Parâmetros 
Curriculares Nacionais (PCNs), compostos de 10 volumes $^{4}$, destinados às quatro primeiras séries do ensino fundamental.

Segundo o Documento Introdutório, os PCNs "constituem um referencial de qualidade para a educação no Ensino Fundamental em todo o país” (Vol. 1, 1997: 13). Ainda, destaca que:

o conjunto das proposições aqui expressas responde à necessidade de referenciais a partir dos quais o sistema educacional do país se organize, a fim de garantir que, respeitadas as diversidades culturais, regionais, étnicas, religiosas e políticas que atravessam uma sociedade múltipla, estratificada e complexa, a educação possa atuar, decisivamente, no processo de construção da cidadania, tendo como meta o ideal de uma crescente igualdade de direitos entre os cidadãos, baseado nos princípios democráticos. Essa igualdade implica necessariamente o acesso à totalidade dos bens públicos, entre os quais o conjunto dos conhecimentos socialmente relevantes" (Vol. 1, 1997: 13. Grifo nosso).

Desta forma, os PCNs procuram dar respostas tanto às demandas de melhoria da qualidade do ensino, como estabelecer "padrões de desempenho do conjunto da população brasileira que melhor correspondam às exigências de inserção do país na nova ordem mundial" (Barreto, 1998: 36).

É importante destacar que o processo de implantação dos PCNs no Brasil não é algo isolado. Durante a década de 80, diversos países (Espanha, Estados Unidos, Inglaterra, Argentina, entre outros) empreenderam uma reformulação curricular, implantando um currículo nacional. Segundo MOREIRA (1996) tais reformulações tem sido associadas à visão neoliberal de educação, o que tem provocado a crítica de diversos educadores a essas reformas educacionais.

Segundo o mesmo autor, um dos possíveis efeitos do processo de implantação de um currículo nacional, como é o caso dos PCNs, é a desqualificação do educador já que, assim como nos livros didáticos, submete-se o profissional a prescrições detalhadas, separando, mais uma vez, em diferentes instâncias, concepção e execução da prática pedagógica.

Ainda, baseando-se em reflexões de Aplle, MOREIRA nos apresenta uma segunda conseqüência de tal processo:

As demandas burocráticas que costumam acompanhar a implementação das propostas de currículo nacional sobrecarregam os docentes e reduzem o tempo livre para descanso, para o lazer e para o aperfeiçoamento. Deixa de haver tempo para um trabalho de

\footnotetext{
${ }^{4}$ Os Parâmetros Curriculares nacionais ( $1^{\mathrm{a}}$ a $4^{\mathrm{a}}$ série) estão estruturados nos seguintes volumes: volume 1 - Introdução aos Parâmetros Curriculares Nacionais; volume 2 - Língua Portuguesa; volume 3 - Matemática; volume 4 - Ciências Naturais; volume 5 - História e Geografia; volume 6 - Arte; volume 7 - Educação Física; volume 8 - Apresentação dos Temas Transversais e Ética; volume 9 - Meio Ambiente e Saúde; volume 10 - Pluralidade Cultural e Orientação Sexual.
} 
qualidade: passa-se a fazer somente o essencial. O trabalho bem feito termina sendo substituído pelo trabalho que simplesmente se cumpre. A conseqüência, diz Aplle, é que os professores vêm a depender mais dos especialistas, que lhes dizem o que fazer, e acabam desvalorizando o conhecimento que adquiriram ao longo dos tempos"(1996: 14).

Assim, com o tempo em boa parte consumido no cumprimento de exigências burocráticas, com pouco tempo para refletir sobre o projeto curricular em processo de implantação, os profissionais da educação acabam se rendendo às detalhadas prescrições, submetendo-se às determinações de especialistas. Mais grave ainda é a conseqüente desvalorização do saber docente construído ao longo da carreira, secundarizado diante de determinações tecnocráticas.

Nesse mesmo sentido caminham algumas conclusões de BARRETO (1998) sobre a política de reformulação curricular em curso no Brasil. Segundo a autora:

A tarefa que se propôs o ministério excedeu em muito o propósito de oferecer parâmetros curriculares. Segundo parecer do próprio Conselho Nacional de Educação, estes constituiriam um conjunto de princípios e conteúdos básicos, capazes de servir como referencial aberto e flexível para orientar o trabalho de formulação das orientações curriculares a ser realizado pelos estados e municípios enquanto gestores do ensino fundamental. Tal como estão, as orientações vão de encontro com o princípio federativo e chegam mesmo a se contrapor à própria noção de currículo, cuja efetivação supõe o trabalho de professores e alunos no cotidiano escolar e dentro do respeito à autonomia das escolas (1998: 39/40)

Continua a mesma autora:

Tudo indica, porém, que, se prevalecerem tais orientações federais extensas e detalhadas, que roubam o espaço a formulações diversificadas em qualquer instância, tenderá a ocorrer uma excessiva homogeneização, senão da prática escolar, certamente do discurso que a informa. Essa homogeneização será tanto maior quanto mais eficiente for o ministério na divulgação de suas propostas por meio de forte articulação com as editoras de livros didáticos, da implementação de programas de capacitação de docentes à distância e da expansão dos processos de monitoramento dos sistemas de ensino através da avaliação externa. Isso ocorre exatamente no momento em que se preconiza a descentralização e em que mais se defende o pluralismo de idéias e a importância das diferenças (1998: 40). 
Diante do que foi até aqui exposto cabe indagar: qual a concepção de formação continuada subjacentes à política educacional implementada pelo Ministério da Educação e que tem dado sustentação a diversos projetos de formação em serviço no Brasil?

Alicerçado no discurso da modernização da economia e do estado, o governo federal centraliza suas ações, reduzindo a participação da sociedade, chamada a opinar apenas sobre assuntos periféricos. Essa lógica administrativa centralizadora, embora de forma não muito clara, esta presente no campo educacional. FREITAS (1995), após rever a literatura educacional internacional ${ }^{5}$, apresenta-nos as seguintes idéias:

Tenta-se passar a idéia de que o professor deve ter autonomia, que a administração deve ser descentralizada, participativa, mas, no entanto, este processo 'democrático' deve servir a interesses centralizados e não aos interesses dos professores, alunos ou das classes populares. Em suma, aumento do controle central combinado com autonomia na execução local. O que se vê emergir como modelo (...) é o desenvolvimento de formas participativas em um contexto em que a política está sendo traçada fora da escola, sendo que os professores estão sendo incorporados (cooptados) apenas para implementar detalhes (1995: 95).

Nesse sentido, a formação continuada do educador, proposta pelos órgãos e instituições ligadas ao poder central, passam a preocupar-se muito mais com o treinamento do educador, responsável, em última instância pela implementação das reformas educacionais, do que com uma formação técnica e política que permita a esse profissional repensar, criticar e mesmo superar essas reformas educacionais. Corre-se, portanto, o risco de empobrecimento na formação do educador, reduzida a cursos de curta duração e com um caráter puramente prático, ou seja, cursos que ensinam a fazer. Desta forma, não é de se estranhar a super valorização da prática na formação do profissional educador e tão pouco a intensificação da atuação de técnicos/especialistas, responsáveis pela elaboração e execução de projetos de formação continuada.

As discussões até aqui realizadas sobre a exclusão dos educadores do processo de discussão sobre a educação no país, a intensificação da atuação de técnicos na formulação e implementação de políticas educacionais, a ênfase na prática em detrimento de uma formação

\footnotetext{
${ }^{5}$ Freitas refere-se diretamente aos seguintes trabalhos: Smyth, J. "International Perspectives on Teacher Collegiality: a labour process discussion based on the concept of teacher's work. British Journal of Sociology of Education, 1991,12 (3), pp. 323-346; Bartlett, L.; Knight, J. e Lingard, B. "Restructuring teacher education in Austrália." British Journal of Sociology of Education, 1992, 13 (1), pp. 18-36.
} 
que articule a formação técnica, teórica e política, a reformulação do sistema educacional a partir de necessidades econômicas, permite-nos concluir que vivemos uma reedição do Tecnicismo Educacional dos anos 70, agora retomado em novas bases, para se adequar ao contexto de globalização e de sofisticação do aparato produtivo.

Por fim, como nos diz SANTOS (1999), a proliferação de programas de formação continuada no país sofre a influência direta das políticas do Banco Mundial. Segundo TORRES (1998), o Banco Mundial, baseando-se na relação custo-benefícios, considera que a qualidade educativa:

seria o resultado da presença de determinados "insumos" que intervêm na escolaridade. Para o caso da escola de primeiro grau, consideram-se nove fatores como determinantes de um aprendizado efetivo, nesta ordem de prioridades, segundo a percentagem de estudos que revelariam uma correlação e um efeito positivo (...): (1) bibliotecas; (2) tempo de instrução; (3) tarefas de casa; (4) livros didáticos; (5) conhecimentos do professor; (6) experiência do professor; (7) laboratórios; (8) salário do professor; (9) tamanho da classe. Desses pontos, deriva o BM suas conclusões e recomendações aos países em desenvolvimento sobre os insumos a priorizar em termos de políticas e alocação de recursos (1998: 134).

Ainda, de acordo com a autora, ao mesmo tempo em que se desestimula o investimento em laboratórios, salário de professores e tamanho da classe, recomenda o investimento especialmente em três deles:

a) aumentar o tempo de instrução, através da prolongação do ano escolar, da flexibilização e adequação dos horários, e da atribuição de tarefas de casa;

b) proporcionar livros didáticos, vistos como a expressão operativa do currículo e contando com eles como compensadores dos baixos níveis de formação docente. Recomenda aos países que deixem a produção e distribuição dos livros didáticos em mãos do setor privado, que capacitem os professores na sua utilização, além de elaborar guias didáticos para estes últimos; e

c) melhorar o conhecimento dos professores (privilegiando a capacitação em serviço sobre a formação inicial e estimulando as modalidades a distância (1998: 135. Grifos da autora)

Como podemos perceber, existe uma tendência a super valorização da capacitação em serviço em detrimento da formação inicial do educador o que nos parece um grande equívoco. Embora o processo de formação continuada seja um momento fundamental no processo de 


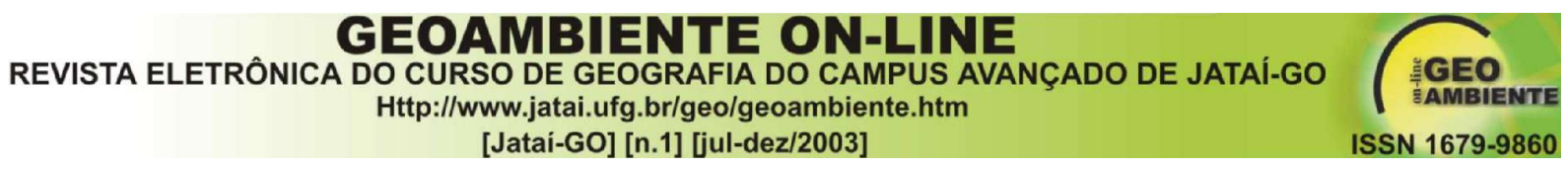

reflexão sobre a prática educacional, de busca de caminhos para a superação dos obstáculos encontrados no cotidiano escolar e, ainda, como um momento de atualização do profissional educador, privilegiar capacitação em serviço em detrimento da formação inicial é separar um processo de preparação, de profissionalização e de atualização permanente do educador que é uno, indissociável.

\section{5 - CONCLUSÃO}

Neste ponto de nosso trabalho tentaremos estabelecer alguns princípios que possam (talvez) servir de referencial para se discutir uma política de formação continuada do educador no $\mathrm{CAJ} / \mathrm{UFG}$.

Em primeiro lugar, consideramos fundamental que o conjunto dos profissionais da educação, juntamente com o seu sindicato, possam participar ativamente do processo de discussão e de elaboração de uma política de formação continuada a ser implementada pelo $\mathrm{CAJ} / \mathrm{UFG}$. Isso significa dizer que uma política de formação continuada não pode desconsiderar as necessidades do conjunto dos educadores. Nesse sentido, busca-se romper uma relação hierárquica e autoritária estabelecida historicamente entre as instituições formadoras e os educadores onde estes últimos sofrem a ação das primeiras tidas como detentoras de todo o saber, fonte das inovações educacionais, etc...

Em segundo lugar, deve-se buscar a criação de vínculos mais estreitos entre as instituições empregadoras e as instituições formadoras. Nesse sentido, propomos a criação de um CENTRO DE FORMAÇÃO CONTINUADA DO EDUCADOR no Campus Avançado de Jataí onde estejam representados os profissionais da educação da rede ${ }^{6}$ municipal, estadual e particular de ensino, as Secretarias de Educação Estadual e Municipal, o CAJ/UFG e o CEFET. Este Centro canalizaria as energias, até o momento dispersas, no sentido de melhor compreensão das necessidades educacionais, não somente do município de Jataí, mas de toda a região do Sudoeste de Goiás. Consideramos importante que o CENTRO tenha sua sede no CAJ/UFG já que é esta instituição que concentra o maior número de cursos de licenciatura no município bem como um grande número de profissionais que se dedicam permanentemente à reflexões sobre a educação,

\footnotetext{
${ }^{6}$ É importante se frisar que hoje, tanto o CAJ/UFG como o CEFETE, atendem alunos de vários municípios do Sudoeste Goiano em seus cursos de licenciatura, o que justifica a ampliação das atividades do CENTRO para além dos limites do Município de Jataí.
} 


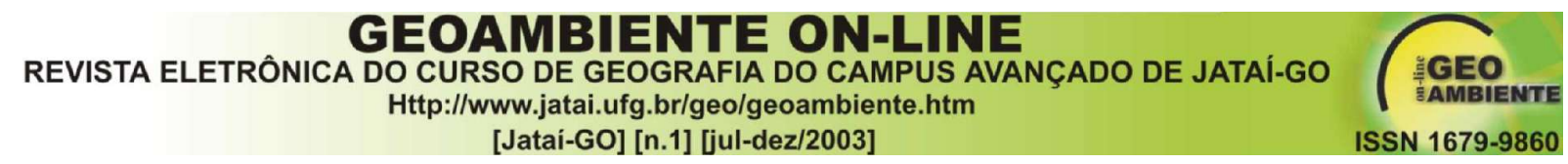

possuindo, desta forma, as melhores condições para articular uma política de formação continuada consistente e que contemple os interesses dos profissionais da educação, dos órgãos formadores e empregadores.

Em terceiro lugar, qualquer política de formação continuada do profissional da educação deve articular teoria e prática, contribuindo para uma formação mais consistente do educador. Nesse sentido, não podemos reduzir a formação continuada do educador à resolução de problemas práticos do seu dia-a-dia. Isso seria reproduzir a visão do educador como prático. É de extrema relevância que se consiga dar respostas aos problemas cotidianos que emergem no espaço escolar. Mas estes devem estar articulados a uma visão mais ampla sobre o processo educativo e sobre a sociedade local, nacional e mesmo internacional. Ou, em outras palavras, devemos articular aspectos práticos com uma consistente formação teórico/política do profissional educador.

\section{6 - BIBLIOGRAFIA}

BARRETO, Elba Siqueira de Sá. Tendências recentes do Currículo do Ensino fundamental no Brasil. Os currículos do ensino fundamental para as escolas brasileiras. Campinas, São Paulo. Autores associados, Fundação Carlos Chagas, 1998. (Coleção formação de professores)

BRASIL. Ministério da Educação. Secretaria de Educação Fundamental. Referenciais para formação de Professores. Brasília, 1999.

. Secretaria de Educação Fundamental. Parâmetros Curriculares Nacionais: Introdução aos Parâmetros Curriculares Nacionais. Brasília: MEC/SEF, 1997.

GOIÁS. Secretaria da Educação. Diretrizes e Bases do Sistema Educativo do Estado de Goiás. 1998.

LÜDKE, Menga. "Sobre a socialização profissional de Professores". Cadernos de Pesquisa. N. 99, São Paulo, 1996. (p. 5-15)

MOREIRA, Antônio Flávio. Os parâmetros curriculares nacionais em questão. In. Educação \& Realidade. V. 1, n. 1. Universidade Federal do Rio Grande do Sul, Faculdade de Educação, Porto Alegre, fev. 1976. (p. 9 a 22)

REALE, Aline M. de M. R. O desenvolvimento de um modelo construtivo - colaborativo de formação continuada centrado na escola: relato de uma experiência. Cadernos CEDES. N. 36, Campinas, São Paulo, 1995. (p. 65 - 76) 


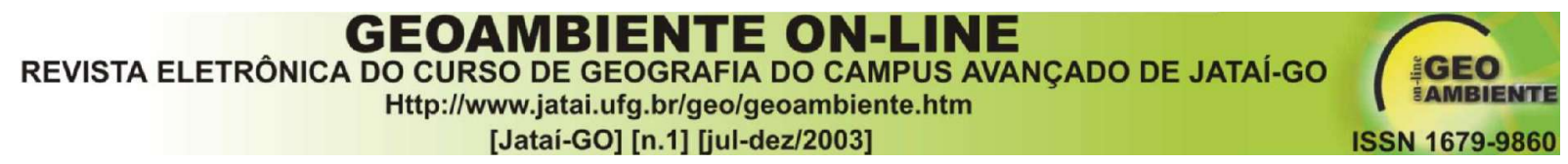

SANTOS, Lucíola Licínio de Castro Paixão. A formação contínua. 1999. (mímeo)

TARDIF, Maurice et alii. Os professores face ao saber: esboço de uma problemática do saber docente”. Teoria da Educação, n. 4, 1991.

TORRES, Rosa Maria. Melhorar a qualidade da educação básica? As estratégias do Banco Mundial. In: O Banco Mundial e as Políticas Educacionais. Tommasi, Lívia De.Warde, Miriam Jorge. Haddad, Sérgio. (Organizadores). São Paulo, Cortez, 1998. 